\title{
Construções freudianas acerca do sadismo e do masoquismo: uma ruptura com a tradição médica
}

\author{
Freudian constructions about sadism and masochism: a rupture with the medical tradition
}

${ }^{[a]}$ Graduação em Psicologia pela Pontifícia Universidade Católica do Paraná, Toledo, PR - Brasil, e-mail:

camila.perachi@gmail.com

${ }^{[b]}$ Graduação em Psicologia pela Pontifícia Universidade Católica do Paraná, Toledo, PR - Brasil, e-mail: leka_royer@hotmail.com

${ }^{[c]}$ Graduação em Psicologia pela Pontifícia Universidade Católica do Paraná, draduação em Filosofia pela Universidade Estadual do Oeste do Paraná e mestranda em Filosofia pela Universidade Estadual do Oeste do Paraná, Toledo, PR - Brasil, e-mail: tamarapasqualatto@hotmail.com

[d] Especialista em Psicanálise pela Universidade de Marília, mestre em Filosofia pela Pontifícia Universidade Católica do Paraná, docente do curso de Psicologia e coordenadora da Pós Graduação em Psicanálise Clínica - de Freud a Lacan, Pontifícia Universidade Católica do Paraná, Toledo, PR Brasil, e-mail: michaella.laurindo@pucpr.br

Recebido: 06/12/2012 Received: 12/06/2012

Aprovado: 30/07/2013 Approved: 07/30/2013

\author{
Camila Taiara Perachi[ ${ }^{[a]}$, Letícia Royer ${ }^{[b]}$, Tamara Havana dos Reis Pasqualatto ${ }^{[c]}$, Michaella Carla Laurindo ${ }^{[d]}$
}

\section{Resumo}

As práticas perversas sempre foram consideradas pela sociedade como desviantes e até criminosas. Muitos autores criaram obras relevantes a respeito, como Krafft-Ebing, que define os perversos como "filhos ilegítimos da natureza", doentes que necessitavam de tratamento. No entanto, Sigmund Freud vem romper com a tradição médica e lançar um novo olhar sobre este fenômeno. Neste sentido, o presente artigo de revisão bibliográfica veicula o proposto tema - perversão sádica e masoquista no entendimento freudiano - no intuito de mostrar as contribuições da psicanálise e como Freud foi modificando no decorrer da prática sua teoria. Ao discorrer sobre o tema, identificamos três momentos significativos na construção da teoria das pulsões, relativo à perversão. Assim, pode-se mostrar que aquilo que os homens horrorizam nos perversos, na verdade, faz parte de cada um, em maior ou menor grau. A fim de ilustrar sadismo e masoquismo, foram utilizados excertos das obras de Sade e Sacher-Masoch.

Palavras-chave: Freud. Perversão. Sadismo. Masoquismo.

\section{Abstract}

The perverse practices always were considered by society as deviants and even criminals. Many authors created relevant works about it, such as Krafft-Ebing, who defines the perverse people as "stepchildren of nature". However, Sigmund Freud comes to break up with the medical tradition and to set up a new way of looking at this phenomenon. In this sense, this article of bibliographic revision conveys the proposed theme - sadism and masochism in perversion - with the intention of showing the contributions of psychoanalysis and the way that Freud had modified, through his practice, the theory about this theme. It was found that there are three significant moments in the construction of the instinct theory, concerned to perversion. It was shown that those things that horrify men about perverse people, in fact, are parts of each man, in higher or lower degree. Aiming to illustrate the sadism and the masochism, it had been used excerpts of productions of Sade and Sacher-Masoch.

Keywords: Freud. Perversion. Sadism. Masochism. 


\section{Introdução}

A literatura a respeito da perversão evidencia que há uma ruptura entre o discurso psiquiátrico e o psicanalítico, justamente no que se refere à compreensão do fenômeno perverso. A psiquiatria lida com tal fenômeno como se fosse uma doença, passível de ser tratada e até mesmo curada. Freud, por sua vez, percebe nele um traço característico do ser humano, afirmando que a agressividade é inerente ao mal e, portanto, não pode ser curada ou exterminada. A constatação dessa divergência impõe uma questão: quais são os aspectos da teoria freudiana que permitiram sua compreensão ímpar do humano e principalmente da perversão?

0 intuito de evidenciar a supracitada ruptura exige uma breve reconstrução histórica da questão, bem como uma atualização sobre o discurso psiquiátrico a partir do DSM - IV. Só então é possível passar à teoria freudiana acerca das perversões especificamente sádica e masoquista - que foi aqui dividida em três momentos, de acordo com a evolução da teoria das pulsões. Cada momento diz respeito a um período, que contém pelo menos um texto principal sobre a dinâmica pulsional. 0 primeiro abrange os anos de 1905 a 1914; o segundo 1915 a 1919; e o terceiro 1920 a 1939.

A ênfase no sadismo e no masoquismo se justifica pela sua importância literária - desde KrafftEbing, foram consideradas perversões cardeais - e teórica: Freud deu específica atenção a elas, afirmando que "o sadismo e o masoquismo ocupam entre as perversões um lugar especial, já que o contraste entre atividade e passividade que jaz em sua base pertence às características universais da vida sexual" (FREUD, 1905, p.150).

Apesar de a teoria freudiana constituir um contraponto com o pensamento psiquiátrico e lançar luz sobre quão exclusivamente humano é o fenômeno perverso, as consequências de suas descobertas ainda estão reduzidas a consultórios psicanalíticos, não ressoando em outras áreas. É possível perceber que a perversão ainda é vista como um fenômeno sombrio, marginal, execrável e patológico. A ausência de estudos atuais sobre a perversão sugere que ela ainda constitui um desafio para os homens, e por isso é um convite a ser pensada.

\section{Contextualização histórica, social e psiquiátrica da noção de perversão com ênfase no sadismo e no masoquismo}

Antes do século XIX, a sexualidade humana estava sob o julgo da lei e daqueles que respondiam por ela. Dessa forma, determinadas práticas sexuais como fetichismo, felação, flagelação e masturbação eram condenadas legalmente. A perversão é um termo muito antigo, que tem sua origem na teologia moral cristã e significa "inversão do suposto natural, ou seja, refere-se a todas as formas de pecar quanto ao sexo" (FLEIG, 2008, p.16).

Com o advento do referido século, muitas mudanças aconteceram, inclusive na forma de compreender e tratar a sexualidade. No entanto, o termo com conotação moral e cristã, "perversão", permaneceu. Com a mudança no código penal francês - que por sua vez influencia todos os países europeus - as práticas sexuais são laicizadas. A única condição é que pratiquem sua sexualidade fora do alcance dos olhos da sociedade, ou seja, que não se exponham, de modo a não ferir a moral pública, e que essa prática seja realizada entre adultos com o assentimento de ambos. À lei cabe, portanto, proteção aos menores, punir os escândalos e condenar abusos e violências contra parceiros não consentâneos. Desse modo, práticas sexuais outrora julgadas perversas, não são mais passíveis de condenação. Agora a sexualidade considerada desviante está a cargo da ciência médica (ROUDINESCO, 2008).

Como as práticas sexuais não foram mais julgadas legalmente, foi necessário criar uma distinção entre o bom perverso e o mau perverso. Entre aqueles passíveis de serem tratados e curados, capazes de se reintegrar à sociedade, e aqueles considerados provenientes de uma "classe perigosa". Estes últimos, portanto, deveriam ser afastados do convívio social (ROUDINESCO, 2008).

Neste contexto, a palavra "perversão", incorporada pela psiquiatria, toma sentido geral. Torna-se o nome genérico de todas as anomalias sexuais e tem seu primeiro uso médico em 1842, no Oxford English Dictionary. Na França, a palavra é inaugurada em 1849, com o psiquiatra Claude-Franadsçois Michéa e é incorporada a todas as línguas europeias (ROUDINESCO, 2008). Outros grandes nomes da psiquiatria, responsáveis por criar obras relevantes sobre as perversões, são Heirinch Kaan e Krafft-Ebing. 
A partir desse momento no discurso da medicina psiquiátrica do século XIX, é considerado perverso e, consequentemente, patológico,

aquele que escolhe como objeto o mesmo que ele (homossexual), ou ainda a parte ou o desejo de um corpo que remete ao seu próprio (o fetichista, o coprófilo). (...) aqueles que possuem ou penetram por efração o corpo do outro sem seu consentimento (estuprador, o pedófilo), os que destroem ou devoram ritualmente seus corpos ou o dos outros (o sádico, o masoquista, o antropófago, o autófago, o necrófago, o necrófilo, o escarificador, o autor de mutilações), os que travestem seus corpos ou sua identidade (o travesti), os que exibem ou apreendem o corpo como objeto de prazer (o exibicionista, o voyeurista, o narcísico, o adepto do autoerotismo). É perverso, enfim, aquele que desafia a barreira das espécies (o zoófilo) nega as leis da filiação e da consanguinidade (o incestuoso) ou ainda contraria a lei da conservação da espécie (o onanista) (ROUDINESCO, 2008, p.82).

A função dessa nova classificação, bem como da criação de novas terminologias para designar as perversões, é dar um "fundamento antropológico" ao sexo e ao crime sexual, que permita distinguir a sexualidade dita normal da patológica. Para isso, a semiologia e a taxonomia, a serviço do desejo da elite dominante da época, identificavam, rastreavam, mensuravam e controlavam todas as práticas sexuais. Mas mesmo os estudiosos, pioneiros da sexologia, tinham dificuldade em chegar a um consenso sobre os fundamentos, sobre as causas da perversão. Alguns acreditavam que era um fenômeno natural no reino animal. Outros, ao contrário, pensavam que as perversões eram adquiridas e exclusivas da espécie humana. Havia aqueles, ainda, que sustentavam que era resultado de uma patologia hereditária transmitida na infância por má educação.

Em 1844, em Leipzig, é publicada a primeira obra que trata especificamente das psicopatologias sexuais: Psychopathia Sexualis, do psiquiatra russo Kaan. Quem ressalta a importância dessa obra como precursora da noção de perversão é Michel Foucault (2001), em Os anormais. Pelo fato de o estudo de Kaan ter sido publicado em latim e nunca traduzido, Foucault é a porta de acesso a ela. Em 1886, KrafftEbing publica sua Psychopathia Sexualis. Ambos autores nomeiam suas obras com o mesmo título. As ideias e conceitos do psiquiatra alemão, por sua vez, serviram de fundamento às classificações das perversões sexuais bem como influenciariam as noções psicanalíticas sobre perversão.

A obra de Richard Von Krafft-Ebing constitui a síntese mais rigorosa de todas as correntes da sexologia e nela define os perversos como "filhos ilegítimos da natureza" (KRAFFT-EBING, 1965, p.9). Para ele, os perversos eram mentalmente doentes, tinham a vida sexual invertida e isso representava a vitória da animalidade sobre a civilização. Todavia, acreditava que a ciência poderia um dia curar esses "desafortunados". 0 psiquiatra alemão divide o que chamou de "anomalias do instinto sexual" em quatro classes: anestesia do instinto sexual, hiperestesia do instinto sexual, paradoxia do instinto sexual e, por fim, parestesia do instinto sexual.

Desta forma, em parte de sua obra, realiza a descrição e a categorização exaustiva das perversões sexuais, por ele denominadas "parestesias do instinto sexual", grupo no qual se encontram o sadismo e o masoquismo, que foram por ele consideradas as perversões cardeais. Segundo Krafft-Ebing (1965, p. 53), "Com a oportunidade de satisfazer naturalmente o instinto sexual, cada expressão deste que não corresponda ao propósito da natureza - propagação - deve ser entendida como perversa". Ainda divide as parestesias em: sadismo, masoquismo, fetichismo e sexualidade antipática (homossexualidade). Diante da importância dos dois primeiros para este estudo, exclusiva ênfase será dada neles e afirma que o sadismo seria uma associação de crueldade e violência ativa com luxúria:

É a experiência de sensações sexuais prazerosas (incluindo o orgasmo) produzidas por atos de crueldade, punição corporal infligida a si mesmo ou testemunhada por outros, sejam eles animais ou seres humanos. Pode também consistir de um desejo inato de humilhar, machucar, ferir ou até mesmo destruir outros a fim de criar prazer sexual para si mesmo (KRAFFT-EBING, 1965, p.53).

0 autor ainda percebe que este fenômeno é mais comum em homens devido à posição ativa que o sujeito assume, em oposição à posição passiva, representada pela mulher. 0 que acontece nos sádicos é que as forças inibitórias que deveriam emergir e impedir um ato de violência extremo e impulsivo são muito fracas (KRAFFT-EBING, 1965). 
Em oposição ao sadista, encontra-se o masoquista, que é aquele que sente prazer em ser violentado, humilhado, em sofrer e sentir dor provocada a ele por outra pessoa. 0 psiquiatra define:

\begin{abstract}
por masoquismo eu entendo a perversão peculiar da vida sexual psíquica na qual o individuo afetado em sentimento e pensamento sexual, é controlado pela ideia de ser completamente e incondicionalmente sujeito à vontade de uma pessoa do sexo oposto; de ser tratado por esta pessoa como que por um mestre, humilhado e abusado. Esta ideia é reforçada pelo sentimento de luxúria; o masoquista vive em fantasias, nas quais cria situações deste tipo e frequentemente tenta realizá-las (...) (KRAFFT-EBING, 1965, p. 86).
\end{abstract}

Além das descrições e categorização das perversões, ao psiquiatra é atribuído os créditos pela criação do neologismo "masoquismo". Ele o cria baseado na obra de Sacher-Masoch, pois afirma que este frequentemente fazia desta perversão a base de suas obras. Para Krafft-Ebing, Masoch não apenas descrevia essa perversão, mas sofria dela: era um masoquista, e, ainda, era um exemplo da influência exercida pela vida sexual sobre a formação e direcionamento da mente do homem.

Há na obra vários casos de pacientes que sentiam prazer e só conseguiam uma ereção quando eram maltratados, torturados ou espancados. A maioria dos pacientes masoquistas relata possuir tal desejo desde a infância, ainda que na época não pudessem reconhecer seu cunho sexual. Acredita que, tanto o sadismo quando o masoquismo são patologias congênitas, oriundas de uma má hereditariedade. Considera que essas duas manifestações sexuais formam um par perfeito, pois, enquanto no sadismo há um desejo de infligir dor e fazer uso da violência, no masoquismo há um desejo de sofrer e ser sujeitado à violência. Sendo assim, todos os atos e situações utilizados pelo sadista no papel ativo tornam-se objeto de desejo do masoquista no papel passivo. Assegura ainda que o indivíduo sádico ou masoquista também possa ser um "invertido" sexualmente, ou seja, homossexual (KRAFFT-EBING, 1965).

Esse autor foi um grande expoente dessa temática, no entanto, desde a publicação de Psychopathia Sexualis, que certamente influenciou as concepções e pesquisas sobre esse assunto, poucas coisas se modificaram. A psiquiatria contemporânea, quanto às classificações e compreensão da perversão, e mais especificamente na compreensão do sadismo e do masoquismo, não representa grandes avanços em relação à obra de 1886. Atualmente, as classificações e descrições de todos os transtornos mentais são feitas pela Associação Americana de Psiquiatria (APA), publicada no chamado Manual de diagnósticos e estatísticas das perturbações mentais (DSM ${ }^{1}$ ), que se encontra em sua quarta edição.

As perversões, segundo o Manual diagnóstico e estatístico de transtornos mentais - DSM-IV (2002) são agrupadas sob a denominação de parafilias. São caracterizadas por anseios, fantasias ou comportamentos sexuais recorrentes e intensos que envolvem objetos, atividades ou situações incomuns, objetos não humanos, sofrimento ou humilhação, próprios ou do parceiro, crianças ou outras pessoas sem o seu consentimento.

Do sadismo sexual, o DSM - IV (2002), afirma que consiste na imaginação parafílica posta em ação com um parceiro não consentâneo, causando-lhe dano. Já o masoquismo é compreendido como ferimentos autoinfligidos sob influencia da imaginação parafílica. Os dois têm em comum o fato de que os relacionamentos sociais e sexuais podem ser prejudicados caso terceiros considerem esse comportamento sexual incomum, vergonhoso ou repugnante ou se o parceiro sexual do indivíduo recusar-se a cooperar com essas preferências.

O DSM - IV aponta que alguns comportamentos ou fantasias associadas com essas parafilias podem iniciar na infância ou nos primeiros anos da adolescência, mas se intensificam na adolescência ou idade adulta. 0 diagnóstico é dado apenas quando os sintomas permanecerem por seis meses ou mais, devido ao fato de que só fantasiar de vez em quando ou apresentar comportamentos sexuais incomuns não faz de ninguém um parafilico.

Como se pode perceber, as únicas diferenças entre Psychopathia Sexualis, de 1886 e o DSM - IV, de 2002, são as nomenclaturas utilizadas e a ausência de julgamento moral neste último, que é escrito de forma imparcial e impessoal.

\footnotetext{
1 Sigla do inglês Diagnostic and Statistical Manual of Mental Disorders.
} 


\section{Sadismo e Masoquismo na teoria freudiana}

No século XIX, a psicanálise estruturou-se como uma forma distinta de compreender o psiquismo humano. Com a sua metapsicologia ${ }^{2}$, Freud rompeu com a tradição médica, com paradigmas e preconceitos acerca da sexualidade humana - que ele fez questão de enfatizar: é uma psicossexualidade, ou seja, ultrapassa o fisiológico e tem suas raízes e relações com o psiquismo. A partir desse entendimento, a perversão então pôde ser vista como um fenômeno psíquico e não puramente sexual orgânico. Aquilo que na perversão constitui objeto de horror, Freud diz que, na verdade, faz parte de cada homem, em maior ou menor grau.

Como o recorte dessa pesquisa sobre a teoria freudiana das perversões é o sadismo e o masoquismo, é necessário esclarecer alguns conceitos tais como o de inconsciente, Édipo e também os diferentes momentos da elaboração da teoria das pulsões. Percebendo aspectos não conscientes do psiquismo humano, Freud investiga as relações de fenômenos orgânicos com possíveis causas e desdobramentos psíquicos.

O inconsciente - considerado a maior e mais original descoberta freudiana - pode ser entendido como uma cadeia de conteúdos latentes:

O que Freud denominou "inconsciente" apresentou-se, desde o inicio - desde $A$ interpretação dos sonhos -, como uma série de pensamentos (Gedanken). Uma trama de ideias em estado de latência, pendentes, sob a fachada do sonho com a aparência de um conjunto esparso e contraditório. Entretanto, e contrariamente as aparências, essa trama que a livre associação revela no curso da análise é a expressão material de uma cadeia (GODINO-CABAS, 2010, p.32).

Por pressupor uma dissociação da consciência e perceber relações entre sintomas fisiológicos e conteúdos psíquicos, foi necessário encontrar um elo entre esses fenômenos, por isso Freud (1915/1996b, v. 14, p. 127) elaborou a ideia de pulsão: "um conceito situado na fronteira entre o mental e o somático".

2 Conceito utilizado por Freud pela primeira vez em [1898]1996a, na carta 84, para designar seu modelo psicológico que vai além do estudo da consciência.
No entanto, a pulsão é um conceito que evolui com a teoria e a prática psicanalítica, por isso segue os diferentes momentos da teoria da pulsão em Freud.

\section{0 primeiro momento da teoria das pulsões (1905-1914)}

Com sua primeira tópica formulada, Freud coloca em movimento os conceitos de consciente, pré-consciente e inconsciente e dedica-se demasiadamente às neuroses, principalmente as histéricas, dispensando pouca ou nenhuma atenção às perversões. Valas (1990) esclarece que no começo de sua teoria, o médico austríaco atribuía a perversão à bestialidade humana, inferindo sobre ela julgamento moral, inclusive localizando a essência das perversões nas mulheres, cujos instintos sexuais não teriam sido civilizados suficientemente. Sabendo que Freud foi leitor de Krafft-Ebing, percebemos estreitas ligações entre essas concepções imaturas do psicanalista (que vão sendo retificadas a partir de 1905) com aquelas do médico alemão.

Nos Três Ensaios sobre a Teoria da Sexualidade, Freud (1905/1996c, v.7) dedica-se ao estudo das aberrações sexuais, da sexualidade infantil e das transformações da puberdade. No primeiro ensaio, ele situa as perversões no campo das aberrações sexuais, considerando-as um desvio em relação ao alvo sexual (união dos genitais no coito), porém também aproxima a sexualidade neurótica da perversa: "mesmo no processo sexual mais normal reconhecem-se os rudimentos daquilo que, se desenvolvido, levaria às aberrações descritas como perversões" (1905/1996c, v.7, p.141). Para o psicanalista, as relações com o objeto sexual que antecedem o coito, tal como apalpá-lo, contemplá-lo, beijá-lo, são fatores presentes na "vida sexual normal" que se desenvolvidos, levaria à perversão. Assim, Freud (1905/1996c, v.7, p.142) conceitua: "as perversões são ou (a) transgressões anatômicas quanto às regiões do corpo destinadas à união sexual, ou (b) demoras nas relações intermediárias com o objeto sexual que normalmente seriam atravessadas com rapidez a caminho do alvo sexual final".

Essa definição pode ser ilustrada pelo caso 28 de Krafft-Ebing, em que o alívio da tensão sexual se dá por vias consideradas transgressivas:

Por volta de 1860, os habitantes de Leipzig foram 
aterrorizados por um homem que costumava atacar moças jovens na rua, perfurando-as no braço com uma adaga. Quando finalmente foi preso, reconheceram nele um sádico, que ejaculava, no instante de apunhalar e para quem o ataque às mulheres era um equivalente do coito (KRAFFT-EBING, 2000, p. 36).

Todavia, algumas características perversas podem ser identificadas na infância, reforçando o paralelo entre neurose e perversão. No segundo ensaio, dedicado à sexualidade infantil, Freud afirma que é na criança que ocorrem as primeiras relações e manifestações da psicossexualidade. Com as investigações acerca da sexualidade infantil, conclui que a criança possui uma disposição perversa polimorfa em uma fase normal de sua constituição psíquica.

É instrutivo que a criança, sob a influência da sedução, possa tornar-se perversa polimorfa e ser induzida a todas as transgressões possíveis. Isso mostra que traz em sua disposição a aptidão para elas; por isso sua execução encontra pouca resistência, já que, conforme a idade da criança, os diques anímicos contra os excessos sexuais - a vergonha, o asco e a moral - ainda não foram erigidos ou estão em processo de construção. (FREUD, 1905/1996c, v. 7, p. 180).

Por isso, pode-se dizer que um perverso não se torna perverso, mas antes permanece perverso, ou seja, sua libido permanece fixada na satisfação voltada ao próprio corpo e não a um objeto externo. Com essas considerações, a perversão abandona o status de doença ou de um fenômeno abjeto, para ser elevada não só ao patamar de uma forma de constituição do psiquismo, mas também uma etapa dela, pela qual todos nós passamos. Dessa forma, tornar-se neurótico é passar pelo processo de recalcamento. Com excelência, então, Freud conclui que "a neurose é, por assim dizer, o negativo da perversão" (FREUD, 1905/1996c, v.7, p.157).

Com essa formulação, e com as relações estabelecidas entre a sexualidade neurótica e perversa, o psicanalista concretiza sua ruptura com a tradição psiquiátrica. Com a afirmação de que existem vestígios na constituição do psiquismo humano em que se podem observar traços de perversão, é necessário, portanto, elucidar esse processo, que por sua vez, culminará no complexo de Édipo.
Inicialmente, a satisfação pulsional de um bebê é parcial, ou seja, ela se dá, por exemplo, ora por meio da boca, ora por meio do ânus, e não integrada em todo o corpo. A agenciadora dos objetos que satisfazem as pulsões parciais é a mãe. Quando ocorre o complexo de Édipo, há o início da integração das pulsões parciais, ainda com primazia da zona genital. Por isso, é a primeira vez na vida em que a criança conhece um movimento erótico de todo seu corpo em direção ao corpo do outro, mas um outro especial: o genitor do sexo oposto. Isso configura o desejo incestuoso. A figura da lei que impede o impulso da criança de se realizar é a função paterna. É o pai que impede o filho de satisfazer seu desejo incestuoso, é o rival que o ameaça.

Esse acontecimento é o que Freud identificou como Complexo de Édipo, fazendo referência ao mito do Édipo Rei. Uma das questões do Complexo de Édipo é o temor da castração, por conta da descoberta de que nem todas as criaturas do mundo possuem um falo. Falo é o representante do desejo e sua imagem é o pênis. Não o órgão em si, mas sua imagem fantasiada, idealizada. Essas questões são de tamanha importância, que irão encaminhar o processo do Édipo e posteriormente sua dissolução e o investimento na vida social e escolar. 0 complexo de Édipo dará origem à neurose, à psicose ou à perversão, e também à identificação sexual. 0 clichê mais tradicional do complexo de Édipo é o seguinte: o menino está apaixonado pela mãe e quer afastar o pai.

A relação da mãe com seu filho é que desperta nele a pulsão sexual:

0 trato da criança com a pessoa que a assiste é, para ela, uma fonte incessante de excitação e satisfação sexuais vindas das zonas erógenas, ainda mais que essa pessoa - usualmente, a mãe - contempla a criança com os sentimentos derivados de sua própria vida sexual: ela a acaricia, beija e embala, e é perfeitamente claro que a trata como o substituto de um objeto sexual plenamente legítimo. (...). Ela considera seu procedimento como um amor "puro", assexual, já que evita cuidadosamente levar aos genitais da criança mais excitações do que as inevitáveis no cuidado com o corpo. Mas a pulsão sexual, como bem sabemos, não é despertada apenas pela excitação da zona genital; aquilo que chamamos ternura um dia exercerá seus efeitos, infalivel- 
mente, também sobre as zonas genitais (FREUD, $1905 / 1996$ c, v. 7, p. 210-211).

Essa relação de ternura e afeto que é muito excitante para o bebê, dá origem às pulsões sexuais. Como há pulsão em uma criança, com certeza, haverá Édipo. Assim, nenhuma criança escapa ao Édipo porque ela não pode escapar das pulsões eróticas que lhe afluem e porque nenhum adulto pode evitar ser alvo delas ou tentar bloqueá-las. A passagem pelo Édipo levará a um posicionamento subjetivo frente à castração, ou seja, frente à lei que impede seus desejos de serem realizados.

0 perverso desmente a possibilidade de castração, nega que a mulher - mais precisamente, a mãe - seja castrada, pois admitir isso seria correr o risco de também ser castrado. Isso o leva a ter uma relação simbiótica com a mãe, não cabendo a intervenção de um terceiro (pai, ou lei). Portanto, a mulher para o perverso é uma mulher fálica. Seja por identificação à mãe ou por se colocar no lugar de falo, o perverso assume uma posição de negação da castração.

Sadismo e masoquismo são duas formas de exercer a genitalidade dentro desta forma de constituição; são destinos dados à pulsão para obter a satisfação, são manifestações que só encontram o prazer por outras vias - somente torturar ou ser torturado causa excitação sexual nestes indivíduos. Sacher-Masoch pode ilustrar isso:

A sensação de, como adorador de Wanda, ser maltratado por um rival de melhor sorte é indescritível - eu definhava de vergonha e desespero. E de tudo isso o mais vergonhoso era que eu, em tal lamentável situação, sob o chicote de Apolo e sob o riso cruel de minha Vênus, começava a experimentar uma espécie de prazer fantástico e ultrassensual, com Apolo a alijar da situação toda poesia, e, chibatada após chibatada, na impotência de minha ira, eu só consegui serrar os dentes, em mim desvanecendo o voluptuoso desvario, a mulher e o amor (2008, p.155).

Em Sade (2006, p. 322) também se encontram exemplos: "ele lhe amarra ambas as pernas, até uma de suas mãos nas costas, deixa-lhe na outra mão um pequeno bastão para se defender, em seguida; ele a ataca com duros golpes de espada, infligindo-lhe várias feridas das carnes e vai esporrar sobre as chagas".
Freud entendia que sadismo e masoquismo são dois movimentos inseparáveis do ponto de vista psíquico. Nos Três Ensaios sobre a Teoria da Sexualidade de Freud (1905/1996c, v. 7, p. 150) ele afirma que "o sadismo e o masoquismo ocupam entre as perversões um lugar especial [mesma opinião de Krafft-Ebing], já que o contraste entre atividade e passividade que jaz em sua base pertence às características universais da vida sexual", e assinala em nota que é com base na origem das pulsões que ele atribui ao par de opostos - sadismo-masoquismo - esse lugar, destacando-o da série das outras perversões. Na mesma obra, ele esclarece que a pulsão sexual está intimamente correlacionada à crueldade, atribuindo isso à agressão que está mesclada à pulsão sexual e também ao fato de que "toda dor contém em si mesma a possibilidade de uma sensação prazerosa" (FREUD, 1905/1996c, p. 151). Acrescenta ainda que "a particularidade mais notável dessa perversão reside, porém, em que suas formas ativa e passiva costumam encontrar-se juntas numa mesma pessoa" (FREUD, 1905/1996c, p. 151). Então, todo sádico seria, simultaneamente, um masoquista, sendo que a atividade ou a passividade se desenvolveu em um determinado individuo com maior ou menor grau de intensidade.

Para Freud, a forma ativa - o sadismo - tem sua origem facilmente explicada na sexualidade normal, que tem vestígios de agressão devido a uma condição biológica de vencer a resistência do objeto sexual. A forma passiva - o masoquismo - também poderia ser explicada por essa lógica, abrangendo todas as atitudes passivas frente à vida sexual e ao objeto sexual. Percebe-se aqui que o psicanalista situa sua explicação em um cunho biológico e ontológico para as perversões, diferentemente de Krafft-Ebing, que partia do pressuposto da ocorrência de uma degeneração moral, como aponta Ferraz em seu prefácio à Venus das Peles, de Masoch (2008).

Dessa forma, Freud (1905/1996c, v. 7, p. 150) entende que o masoquismo é um complemento ao sadismo: "o masoquismo não é outra coisa senão uma continuação do sadismo que se volta contra a própria pessoa, que com isso assume, para começar, o lugar de objeto sexual". No referido texto, o autor aponta sua descrença frente à possibilidade de existir um masoquismo primário: "em primeiro lugar, pode-se por em dúvida se ele [o masoquismo] aparece alguma vez como fenômeno primário, 
ou seja, pelo contrário, surge regularmente do sadismo mediante uma transformação" (Freud, $1905 / 1996$ c, v. 7, p. 150). No entanto, em nota acrescentada em 1924, ele retifica essa posição, afirmando o reconhecimento de um masoquismo primário (erógeno).

\section{0 segundo momento da teoria das pulsões (1915-1919)}

Com Pulsões e suas vicissitudes, Freud (1915/1996b, v. 14) dá início a uma série de artigos sobre a metapsicologia com o intuito de definir conceitos fundamentais utilizados em sua teoria que até então permaneceram obscuros. A pulsão, como citado anteriormente, é um dos conceitos mais importantes de sua teoria e é nesta obra que ele a define como sendo:

um conceito situado na fronteira entre o mental e o somático, como representante psíquico dos estímulos que se originam dentro do organismo e alcançam a mente, como uma medida da exigência feita à mente no sentido de trabalhar em consequência de sua ligação com o corpo. (Freud, 1915/1996b, v. 14, p. 127).

Um estímulo que provém de dentro do corpo e atua no psiquismo - em $1915^{3}$, as pulsões são divididas em dois grupos: as pulsões do ego e as pulsões sexuais. São constituídas por quatro elementos, nas palavras de Freud (1915/1996b, v. 14): pressão, objeto, fonte e finalidade. De todos os elementos da pulsão, o único que se manifesta na vida psíquica é a finalidade (FREUD, 1915/1996b, v. 14, p. 127), ou seja, a satisfação.

O movimento pulsional pode ser descrito da seguinte maneira: há uma excitação na fonte, no órgão, de uma determinada força e por isso exige uma ação. A pulsão elege um objeto. Uma ação determinada vai ao encontro desse objeto, que é o meio para atingir o fim do circuito pulsional, diminuindo (nunca interrompendo) a excitação na fonte. Freud isolou essas metamorfoses pulsionais em quatro

\footnotetext{
3 Em 1920, com Além do Princípio do Prazer, Freud reformula os conceitos de pulsões sexuais e pulsões do ego para pulsões de vida e pulsões de morte.
}

destinos: transformação no contrário (amor e ódio), retorno contra a própria pessoa (obsessão ou masoquismo), o recalque e a sublimação. Diante da importância dos dois primeiros destinos para o estudo do sadismo e do masoquismo, eles serão estudados exclusivamente.

Sobre a transformação de uma pulsão em seu oposto original, Freud (1915/1996b) afirma que se transforma em dois processos diferentes: mudança de atividade para passividade e uma reversão de seu conteúdo. A transformação da pulsão no seu contrário afeta apenas as finalidades: a finalidade ativa se torna passiva. É exemplo do primeiro processo o par antitético sadismo-masoquismo, e do segundo a transformação do amor em ódio.

Freud (1915/1996b, p.133) faz um esquema de três fases para melhor elucidar o retorno da pulsão em direção ao ego no caso do masoquismo:

(a) 0 sadismo consiste no exercício de violência ou poder sobre uma pessoa como objeto. (b) Esse objeto é abandonado e substituído pelo eu do indivíduo. Com o retorno em direção ao eu, efetua-se também a mudança de uma finalidade pulsional ativa para passiva. (c) Uma pessoa estranha é mais uma vez procurada como objeto: essa pessoa, em consequência da alteração que ocorreu na finalidade pulsional, tem de assumir o papel de sujeito.

Aqui, a fase $c$ corresponde ao masoquismo e a fase $b$ corresponde à pulsão sádica na neurose obsessiva. Assim, ele ainda não reconheceu a existência de um masoquismo primário, uma vez que o masoquismo seria sempre derivado do sadismo. Nessa época, todo masoquista era, na origem, sádico: aconteceu que aquilo que era voltado para o exterior (causar dor) retornou para o ego do individuo (necessidade de ser torturado, de sentir dor). Obviamente, "não é a dor em si que é fruída, mas a excitação sexual concomitante" (FREUD, 1915/1996b, p.134). Então, no masoquismo, a pulsão sádica sofreria, ao mesmo tempo, reversão ao seu oposto e retorno ao próprio eu. Freud comenta também que uma criança não percebe sua tendência sádica, mas quando esta tendência se transforma em masoquista, a dor causa sensações concomitantes de prazer. A finalidade de sentir dor pode facilmente transformar-se em causar dor pela identificação masoquista do sujeito ao objeto sofredor. 
No texto Uma criança é espancada, Freud (1919/1996d, v. 17) discute uma possível gênese das perversões sexuais. Apresenta a fantasia de espancamento que encontrou na análise de alguns dos seus pacientes para ilustrar a polimorfia perversa encontrada na infância. A fantasia nas meninas parte de um posicionamento edipiano normal, enquanto que nos meninos, a fantasia parte de uma posição invertida em que os meninos tomam o pai como objeto de amor. Entretanto, é importante assinalar que mesmo existindo diferenças entre o menino e a menina, a fantasia de espancamento em ambos remete à ideia de que ser espancado é ser amado. Isso ratifica o modo como a psicanálise concebe a satisfação em ser dominado: trata-se de um corpo erogenizado e articulado às representações mentais inconscientes.

\section{Terceiro momento da teoria das pulsões (1920 - 1940)}

Em 1920, Freud deu início a uma formulação de novos conceitos e mecanismos psíquicos ao ouvir na clínica relatos sobre fenômenos como o sadismo e masoquismo. Essa escuta o levou a conceber que o homem não anseia apenas o próprio "bem". Em Além do Princípio do Prazer (1920/1996e, v. 18), o psicanalista desvenda o mecanismo de compulsão à repetição afirmando que no psiquismo há uma tendência a repetir que está para além do princípio do prazer.

A título de ilustração, o autor cita os sonhos que revivem momentos traumáticos, pois não há aparentemente uma satisfação pulsional prazerosa em reviver uma situação dolorosa. Também observou a brincadeira que denominou de "fort-da", em que a criança joga um objeto para longe de sua visão e depois o recupera com intenso prazer, simulando a ausência e o retorno da mãe, entretanto, a ausência é simulada muito mais frequentemente do que o retorno, assim, também não haveria prazer em reviver a ausência materna.

Nesse artigo, ele reformula os conceitos de pulsão do ego (ou de autoconservação) e pulsão sexual, visto haver pulsões ambíguas no ego e as pulsões sexuais também servirem à conservação do sujeito. Assim, as pulsões do ego são entendidas como pulsões de morte, uma vez que buscam levar o sujeito ao mesmo estado inicial inanimado das coisas: a morte, o inorgânico. As pulsões sexuais funcionam como pulsões de vida, pois direcionam o sujeito à continuidade de si através da reprodução: "as pulsões eróticas, que buscam combinar cada vez mais substância viva em unidades cada vez maiores, e as pulsões de morte, que se opõem a essa tendência e levam o que está vivo de volta a um estado inorgânico" (Freud, 1933/1996f, v. 22, p. 109)

No segundo capitulo de Esboço de Psicanálise, Freud (1940/1996g, v. 23, p. 161) esclarece a fusão entre pulsão de vida e de morte, haja vista que as pulsões de preservação da espécie ou sexuais, também estão ligadas à pulsão agressiva:

Decidimos presumir a existência de apenas duas pulsões básicas, Eros e a pulsão destrutiva. (0 contraste entre as pulsões de autopreservação e a preservação da espécie, assim como o contraste entre o amor do ego e o amor objetal, incide dentro de Eros) (Freud, 1940/1996g, v. 23, p. 161).

É observável no sadismo e no masoquismo que as pulsões de vida e de morte estão amalgamadas. Na obra do Marquês de Sade (2008, pp. 70-71), identificamos uma apologia aos prazeres do sexo, no entanto, uma aversão à reprodução: "observa este preceito, minha querida, pois, afirmo, tenho um tal horror pela propagação que deixaria de ser tua amiga a partir do instante em que estivesses grávida".

Freud (1923/1996h, v. 19, p. 59) afirma que "as pulsões de morte são, por sua natureza, mudas, e que o clamor da vida procede, na maior parte, de Eros." E acrescenta em nota de rodapé: "segundo essa concepção, é mediante a intervenção de Eros que as pulsões destrutivas que são dirigidas para o mundo externo foram desviadas do eu (self)". Também afirma que "Só a partir da ligação entre as duas pulsões, amalgamadas, é que a pulsão de morte se faz ver, a partir do momento em que direciona a agressividade para o mundo externo". Assim, é constatável que, de alguma maneira, o princípio do prazer seria uma manifestação da pulsão de morte, visto que o prazer seria a redução das tensões do organismo, ou ainda a inexistência de tensões, levando a um estado praticamente inanimado, semelhante aos feitos da pulsão de morte.

0 conceito de pulsão de morte muda a compreensão do masoquismo, enunciada de maneira tímida neste momento. Freud (1920/1996e, v. 18, p. 65) especula: 
As observações clínicas nos conduziram, naquela ocasião Três Ensaios sobre a Teoria da Sexualidade de Freud (1905/1996c, v. 7; grifo nosso), à concepção de que o masoquismo, a pulsão componente complementar ao sadismo, deve ser encarado como um sadismo que se voltou para o próprio ego do sujeito. Mas, em princípio, não existe diferença entre uma pulsão voltar-se do objeto para o ego ou do ego para um objeto, que é o novo ponto que se acha em discussão atualmente. 0 masoquismo, a volta da pulsão para o próprio ego do sujeito, constituiria, nesse caso, um retorno a uma fase anterior da história da pulsão, uma regressão. A descrição anteriormente fornecida do masoquismo exige uma emenda por ter sido ampla demais sob um aspecto: pode (grifo de Freud) haver um masoquismo primário, possibilidade que naquela época contestei.

Antes de considerar a pulsão de vida e de morte como apresentada acima, era plausível pensar no masoquismo como unicamente derivado do sadismo. Entretanto, a partir de então, Freud percebe que pode haver um desejo de autodestruição primário, inerente ao indivíduo, abrindo mão da necessidade de a pulsão ser primariamente sádica, para então, se voltar contra o próprio sujeito.

O Ego e o Id (FREUD, 1923/1996h, v. 19) é um dos últimos grandes textos teóricos de Freud, que pode ser considerado uma continuação das ideias semeadas em Além do princípio do prazer, de 1920. Nessa obra, é enunciada claramente a segunda tópica freudiana: os conceitos de Id, Ego e Superego. Freud inicia sua explanação retomando que existem partes do Ego que são inconscientes, por isso a necessidade de uma nova divisão teórica da mente que vai além dos conceitos de consciente, pré-consciente e inconsciente. Assim, Freud (1923,1996h, v. 19, p.39) define: "o ego representa o que pode ser chamado de razão e senso comum, em contraste com o Id, que contém as paixões".

Adiante, retoma as duas classes de pulsões - as pulsões de vida e as pulsões de morte - valendo-se do sadismo como exemplo, para ilustrar a ambiguidade presente na vida mental. Sugere que o componente sádico da pulsão é uma união entre os aspectos pulsionais de Eros e de morte. Já o sadismo enquanto perversão seria uma separação entre esses aspectos e uma predominância da pulsão de morte sobre o componente da vida psicossexual: "a atitude hostil não tinha probabilidade de satisfação; consequentemente - por razões econômicas - ela é substituída por uma atitude amorosa para a qual existe mais probabilidade de satisfação, isto é, possibilidade de descarga." (FREUD, 1923,1996h, v. 19, p. 56).

Por fim, Freud se debruça sobre as relações de dependência do Ego: de um lado, o Ego está sujeito aos desejos do Id; de outro lado, está submetido à lei autoritária do Superego, que muitas vezes é demonstrada através do sentimento de culpa. $\mathrm{Na}$ perversão, o superego falha, e o temor é de uma autoridade externa: a punição da lei civil, por exemplo, uma vez que o perverso leva a ato suas fantasias:

Eugenie - Pois bem, desculpo a Dolmancé, os seus pormenores; mas tu, minha doce amiga? Diz-me, peço-te, o que fizeste de mais terrível em tua vida? Madame - Fui enrabada por quinze homens; fui fodida noventa vezes em vinte e quatro horas, e pela frente como por detrás (SADE, 2008, p. 58).

Em 1924, Freud escreve $O$ problema econômico do masoquismo, um texto em que diferencia o masoquismo erógeno, o moral e o feminino. Também neste artigo elabora a ideia que apresentou em Além do princípio do prazer, $(1920 / 1996 \mathrm{e}, \mathrm{v} .18)$ da possível existência de um masoquismo primário, não derivado do sadismo, corrigindo o que afirmara nos Três Ensaios (1905/1996c, v. 7). O psicanalista começa o artigo já dizendo da impossibilidade, do ponto de vista econômico, de haver uma tendência masoquista pulsional, uma vez que os processos mentais seriam governados pelo princípio do prazer. Entretanto, observa que também existem tensões prazerosas, como a excitação sexual, ainda que o princípio do prazer seja a tendência a evitar ou diminuir qualquer tensão. Por isso, o autor diferencia o princípio de nirvana e o princípio de prazer, antes utilizados como sinônimos, em contraposição ao princípio da realidade: "O princípio de nirvana expressa a tendência da pulsão de morte; o princípio de prazer representa as exigências da libido, e a modificação do último princípio, o princípio de realidade, representa a influência do mundo externo" (FREUD, 1924/1996i, v. 19, p. 178). Esses três princípios, embora por vezes conflitantes, toleram-se. Entretanto, Freud enfatiza que é o princípio do prazer que governa a vida mental.

0 autor retorna ao masoquismo, que pode ser observado em três formas: masoquismo erógeno, 
masoquismo feminino e masoquismo moral. 0 masoquismo erógeno tem traços biológicos e constitucionais e seria o pano de fundo para os outros dois tipos. No masoquismo erógeno primário, parte da pulsão de morte, que é destruidora, não pôde ser desviada para o exterior (sadismo) e permaneceu presa, ou seja, a pulsão retornou ao próprio eu, com o auxilio da excitação sexual, demonstrando que ocorre uma fusão entre as duas classes de pulsão. 0 masoquismo feminino possui fantasias de ser amordaçado, espancado, amarrado, etc. Essas fantasias demonstram que o masoquista deseja ser tratado como uma criança travessa, mas também como uma mulher (ser castrado, ser copulado, dar à luz).

Freud escreve mais um artigo importante para a compreensão das perversões em 1927, no qual reflete sobre o fetichismo e conclui que o fetiche é um substituto para o pênis feminino, em especial o da mãe:

é como se a última impressão antes da estranha e traumática fosse retida como fetiche. Assim, o pé ou o sapato devem sua preferência como fetiche ou parte dela - à circunstância de o menino inquisitivo espiar os órgãos genitais da mulher a partir de baixo, das pernas para cima; peles e veludo como por longo tempo se suspeitou - constituem uma fixação da visão dos pelos púbicos, que deveria ter sido seguida pela ansiada visão do membro feminino; peças de roupa interior, que tão frequentemente são escolhidas como fetiche cristalizam o momento de se despir, o último momento em que a mulher ainda podia ser encarada como fálica (FREUD, 1927/1996j, v. 21, p. 157-158).

Podem-se tomar como exemplo as peles usadas pela personagem Wanda, na obra A Vênus das Peles, de Masoch, que causavam verdadeira excitação em Severin: "é dessa forma que eu esclareço também o significado simbólico da pele como atributo do poder e da beleza"

Mais adiante, o personagem Severin fala de seu peculiar desejo:

Eu já lhe disse diversas vezes que o sofrimento exerce em mim uma atração peculiar. Nada me é mais passível de intensificar a paixão do que a tirania, a crueldade, e sobretudo a infidelidade de uma bela mulher. E sobretudo essa mulher, esse ideal raro advindo da estética do feio, alma de Nero em corpo de Prina, não o posso conceber sem uma pele (SACHER-MASOCH, 2008, p. 61).

Assim, é possível verificar que tanto o sádico quanto o masoquista possuem um objeto fetiche: a dor. Torturar ou ser torturado têm valor de fetiche para eles. Freud (1927/1996j, v. 21) elucida que o fetiche é um objeto eleito pelo perverso para substituir o falo. 0 objeto fetiche garante a satisfação, atesta que o gozo pleno é possível, uma vez que ele é a encarnação do objeto que preenche a falta constitucional do Sujeito. Com este artigo de 1927 acerca do fetichismo, pode-se entender como concluídas as principais ideias freudianas sobre as perversões.

\section{Considerações finais}

A necessidade de dizer o que é a perversão motivou muitos autores a pesquisarem e teorizarem sobre ela. Como vimos, a psiquiatria foi uma das encarregadas de estudar, classificar, e até mesmo de curar a perversão, embora sem êxito. Roudinesco (2008) reflete que não há nada mais perverso do que aquela moral que visa domesticar as paixões humanas, sugerindo que o discurso que pretendia exterminar a perversão não era menos perverso do que ela.

Tanto a psiquiatria clássica quanto a contemporânea parecem não apresentar grandes avanços na compreensão e entendimento do fenômeno. Percebe-se que, em relação ao Psychopathia Sexualis de Krafft-Ebing, o DSM - IV, apresentam poucas evoluções nos esclarecimentos sobre o sadismo e masoquismo.

Assim, ao percorrer o estudo do sadismo e do masoquismo, foi possível compreender que quem reabilitou a presença da perversão - enquanto face humana do mal incontornável ${ }^{4}$ - à civilização foi Sigmund Freud. Para ele, a agressividade não deveria ser exterminada, e nem poderia ${ }^{5}$.

\footnotetext{
4 O termo "mal" é compreendido por Freud como uma força pulsional, por isso é incontornável.

5 "os homens não são criaturas gentis que desejam ser amadas (...), pelo contrário, são criaturas entre cujos dotes instintivos deve-se levar em conta uma poderosa quota de agressividade" (Freud, 1930/1996k, v. 21, p. 116)
} 
Assim sendo, a psicanálise parece ser o único discurso e corpo teórico-prático que superou a concepção de horror envolvida no tema, bem como as tentativas de cura e adestramento. Enfatiza que características consideradas perversas são constituintes do ser humano, presente desde seu nascimento até a morte, podendo-se dizer que um sujeito não se torna perverso, mas antes permanece perverso, ou seja, há uma fixação na satisfação autoerótica, que não se enlaça a um objeto externo como ocorre posteriormente nos indivíduos neuróticos.

Com Freud, podemos compreender que a perversão é uma ocorrência exclusivamente humana. Pois o corpo, como explica a psicanálise, é material, mas também pulsional, ou seja, estritamente relacionado com o psiquismo. Por isso, pode-se compreender a afirmação "ser espancado é ser amado", afinal, o corpo agredido é marcado por uma erogenização e articulado às representações mentais inconscientes, possibilitando a relação existente entre prazer e dor.

Sadismo e masoquismo são exemplos da relação entre prazer e dor. Freud compreendia, dentro da dinâmica pulsional prevista em 1915, que o masoquismo só existia e relação ao sadismo, que ele era um complemento a ele. Com o desenvolvimento de suas investigações, em 1920 ele retifica essa posição, por mudar a compreensão da dinâmica pulsional, podendo assim identificar um masoquismo primário, não derivado do sadismo.

Porém, como aponta Roudinesco (2008), predominantemente, a perversão foi sempre - e ainda é - sinônimo de perversidade, ou seja, de maldade, apontanto para uma espécie de aniquilação, desumanização, ódio, destruição, domínio, crueldade e gozo.

A utilização de excertos das obras de Sade e Masoch foi imprescindível para ilustrar este trabalho. Esses autores adornaram a presente pesquisa com suas obras imponentes e provocantes, que foram na contramão da sociedade da época em que foram produzidas. Observa-se, no entanto, que essas obras não deixaram de pertencer ao campo do proibido e do não moral, apesar de séculos transcorridos até a atualidade. Dessa forma, notam-se poucos avanços quanto aos tabus que a civilização carrega a respeito da perversão.

\section{Referências bibliográficas}

American Psychiatric Association (2002). Manual Diagnóstico e Estatístico de Transtornos Mentais. 4. ed. Porto Alegre: Artes Médicas.

Fleig, M. (2008). O desejo do perverso. Porto Alegre: CMC.

Foucault, M. (2001). Os anormais: curso no Collège de France. São Paulo: Martins Fontes.

Freud, S. (1996a). Carta 84 (1898). In S. Freud. Edição standard brasileira das obras psicológicas completas de Sigmund Freud. Rio de Janeiro: Imago.

Freud, S. (1996b). Os instintos e suas vicissitudes (1915). In S. Freud. Edição standard brasileira das obras psicológicas completas de Sigmund Freud. Rio de Janeiro: Imago.

Freud, S. (1996c). Três Ensaios sobre a Teoria da Sexualidade (1905). In S. Freud. Edição standard brasileira das obras psicológicas completas de Sigmund Freud. Rio de Janeiro: Imago.

Freud, S. (1996d). Uma criança é espancada (1919). In S. Freud. Edição standard brasileira das obras psicológicas completas de Sigmund Freud. Rio de Janeiro: Imago.

Freud, S. (1996e). Além do princípio do prazer (1920). In S. Freud. Edição standard brasileira das obras psicológicas completas de Sigmund Freud. Rio de Janeiro: Imago.

Freud, S. (1996f). Novas conferências introdutórias sobre Psicanálise: Conferência XXXII (1933). In S. Freud. Edição standard brasileira das obras psicológicas completas de Sigmund Freud. Rio de Janeiro: Imago.

Freud, S. (1996g). Esboço de Psicanálise (1940). In S. FREUD. Edição standard brasileira das obras psicológicas completas de Sigmund Freud. Rio de Janeiro: Imago.

Freud, S. (1996h). 0 ego e o Id (1923). In S. Freud. Edição standard brasileira das obras psicológicas completas de Sigmund Freud. Rio de Janeiro: Imago.

Freud, S. (1996i). 0 problema econômico do masoquismo (1924). In S. Freud, Sigmund. Edição standard brasileira das obras psicológicas completas de Sigmund Freud. Rio de Janeiro: Imago.

Freud, S. (1996j). Fetichismo (1927). In S. Freud, Sigmund. Edição standard brasileira das obras psicológicas completas de Sigmund Freud. Rio de Janeiro: Imago. 
Freud, S. (1996k). 0 mal estar na civilização (1930). In S. Freud, Sigmund. Edição standard brasileira das obras psicológicas completas de Sigmund Freud. Rio de Janeiro: Imago.

Godino-Cabas, A. (2010). O sujeito na psicanálise de Freud a Lacan: da questão do sujeito ao sujeito em questão. Rio de Janeiro: Zahar.

Krafft-Ebing, R. V. (1965). Psychopathia Sexualis: with especial reference to the antipathic sexual instinct. New York: Bell Publishing Company.

Krafft-Ebing, R. V. (2000). Psychopathia Sexualis: as histórias de caso. São Paulo: Martins Fontes.
Roudinesco, E. (2008). A parte obscura de nós mesmos: uma história dos perversos. Rio de Janeiro: Zahar.

Sacher-Masoch, L. V. (2008). A Vênus das Peles. Trad. Saulo Krieger. Introdução: Flávio Carvalho Ferraz. São Paulo: Hedra.

Sade, Marquês. (2006). Os 120 dias de Sodoma. São Paulo: Iluminuras.

Sade, Marquês. (2008). Filosofia na alcova. São Paulo: Iluminuras.

Valas, P. (1990). Freud e a perversão. Rio de Janeiro: Jorge Zahar Editor. 